\title{
Reduction of Hematite Pellets with Carbonized Coal in
} a Static Bed*

\section{By J.K. WRIGHT,** K. McG. BOWLING** and A. L. MORRISON**}

\begin{abstract}
Synopsis
The reduction of individual iron ore pellets immersed in coal char was measured at $900^{\circ} \sim 1200^{\circ} \mathrm{C}$ for times up to $3 \mathrm{~h}$. The results were compared with published data for other iron oxidelcarbon systems to evaluate the kinetics of reduction in static beds, rotary and shaft kilns, and in composite pellets. Reaction rates and activation energies measured in these studies were similar to published values obtained with intimate mixtures of iron oxides and comparable types of carbon at temperatures up to $1000^{\circ} \mathrm{C}$, where carbon gasification was rate controlling. However, reduction rates for pellets surrounded by char fell significantly at higher temperatures due to the influence of gas diffusion. Reduction rates for pellets were similar for both static bed and rotary kiln conditions at $1000^{\circ} \sim 1150^{\circ} \mathrm{C}$, and were decreased by internal slag formaiion above $1075^{\circ} \mathrm{C}$. Reduction was further inhibited above $1150^{\circ} \mathrm{C}$ by the formation of dense shells of metallic iron around partly-reduced, slag-rich regions, especially towards the centres of the pellets.
\end{abstract}

\section{Introduction}

The direct reduction of iron ores and pellets with coal-based solid reductants in rotary kilns has been applied commercially in some seven countries using technology developed by at least three industrial groups. ${ }^{1-3)}$ Although this type of process was initially developed to treat lump ores, the severe mechanical stresses imposed on the ore by the rotary tumbling action of the kiln resulted in production of fines (by attrition and degradation) which led to sticking and ringing problems. The situation can be improved by the use of indurated pellets, which are more resistant to degradation, and pellets are now a preferred feed.

Solid carbonaceous reductants are also used in the Kinglor-Metor process, ${ }^{4,5)}$ which employs externallyheated vertical shafts as reaction chambers. Reduction of the ore occurs as in the rotary kiln processes, but there is little relative movement and impact between the reacting lumps of ore and reductant. This process has also been developed to a commercial scale.

In recent years a number of publications concerned with the kinetics of the reduction of iron oxides with carbon have appeared. ${ }^{6-19)}$ The majority of these have considered static bed laboratory systems consisting of either mixtures of finely-divided iron oxides and carbon or green pellets containing carbon reductants. However, the reduction system employed in industrial processes differs from the system used in these studies in that fired pellets or lump ores are reduced with separate carbonaceous materials. Moreover, commercial pellets generally contain $2 \sim 10 \%$ gangue materials consisting mainly of $\mathrm{SiO}_{2}, \mathrm{Al}_{2} \mathrm{O}_{3}$ and fluxing agents such as $\mathrm{CaO}$ and/or $\mathrm{MgO}$. Under reducing conditions these compounds can combine with iron oxides to form relatively low melting point slags which could impede the reduction process. In addition, the use of external carbonaceous reductants means that the reducing gases are not generated in close proximity to the unreacted iron oxides within the pellets. Thus gas diffusion effects could also retard the overall reduction rates.

As there is only limited information on the kinetics of fired pellet/carbon reduction, ${ }^{9,20)}$ the present paper presents the results of an investigation into the reduction of commercial-grade iron ore pellets by carbonized coal in a static bed. The aims of the work were to (1) compare and contrast the reduction behaviour of pellets containing appreciable quantities of gangue materials with the results of other workers on the reduction of pure iron oxides with carbon, (2) compare static bed reduction results with those obtained previously in a rotary kiln, ${ }^{20)}$ and (3) gain a better understanding of the rate-limiting steps operative in solid reductant processes of both the rotaryand shaft-kiln types.

\section{Materials}

Full details of the materials used and preparation of the pellets have been presented elsewhere. ${ }^{20)}$ The iron ore pellets of about 12-mm dia. were of typical blast furnace grade containing $64.7 \% \mathrm{Fe}, 3.9 \% \mathrm{SiO}_{2}$, $2.3 \% \mathrm{Al}_{2} \mathrm{O}_{3}, 0.36 \% \mathrm{CaO}$ and $0.07 \% \mathrm{MgO}$. The pellets had an average compression strength of $320 \mathrm{~kg}$ and a porosity of $17.7 \%$. The carbonized coal (crushed and sized to $\sim 8+1 \mathrm{~mm}$ ) contained $82.3 \%$ fixed carbon and $9.8 \%$ total ash.

\section{Experimental Procedure}

In order to facilitate the analysis of the results, all the reduction tests were done isothermally using a large excess of char $\left(\mathrm{C} / \mathrm{Fe}_{2} \mathrm{O}_{3}=5\right)$. At the beginning of each experiment a single pellet, and two alumina crucibles each containing $20 \mathrm{~g}$ of char, were placed in a preheated silicon carbide resistance furnace. When the pellet and char had reached the furnace temperature, measured by mineral insulated thermocouples in the char beds, the pellet was placed in one of the crucibles and the hot char from the second crucible was quickly poured over the pellet. The pellet was thus surrounded by hot char on all sides. After a selected reaction period, the hot crucible con- 
taining the pellet was removed from the furnace and the contents were quickly poured into a lidded stainless steel box and quenched in an inert gas stream. This procedure was repeated for various times and temperatures in the range $900^{\circ} \sim 1200^{\circ} \mathrm{C}$. The extent of reduction was calculated by weighing the individual pellets before and after reduction.*

A small temperature drop was observed during the transfer of the pellet and char, but the temperature quickly recovered to the set value so that errors due to this cooling effect were minimal.

\section{Results}

The effect of temperature on the extent of reduction of the single pellets with time is shown in Fig. 1 (a) for the four lower temperatures, and in Fig. 1(b) for the two higher ones (with the lower temperature lines (---) shown again for comparison).

$\mathrm{Up}$ to about $1075^{\circ} \mathrm{C}$, the extent of reduction at any given time increased with increasing temperature. However, at higher temperatures and at extents of reduction above $60 \sim 70 \%$, reduction was slower than at $1075^{\circ} \mathrm{C}$, indicating a change in the rate-controlling process at high temperatures.

In Fig. 2, the reduction curves for the static bed tests at $1000^{\circ}, 1075^{\circ}$ and $1150^{\circ} \mathrm{C}$ are compared with the corresponding reduction curves for pellets reduced with the same coal char in a batch rotary kiln. ${ }^{20)}$ There are only small differences between the static bed and rotary kiln results and they show much the same trend.

The static bed reduction results, presented as plots of the natural logarithm of the fraction $(f)$ of oxygen remaining in the pellets against the reaction time, are shown in Figs. 3 to 5 . Straight-line relationships were obtained for the pellets reduced at $900^{\circ} \sim$ $1075^{\circ} \mathrm{C}$ and for the initial portions of the curves at $1150^{\circ}$ and $1200^{\circ} \mathrm{C}$. Two reaction stages were distinguished at $900^{\circ}, 950^{\circ}$ and $1000^{\circ} \mathrm{C}$. Microscopic examination of these pellets reduced for short times showed that the pellet edges were initially reduced to magnetite and wustite only. The change in slope of the reduction plots corresponded to the appearance of metallic iron. At higher temperatures metallic

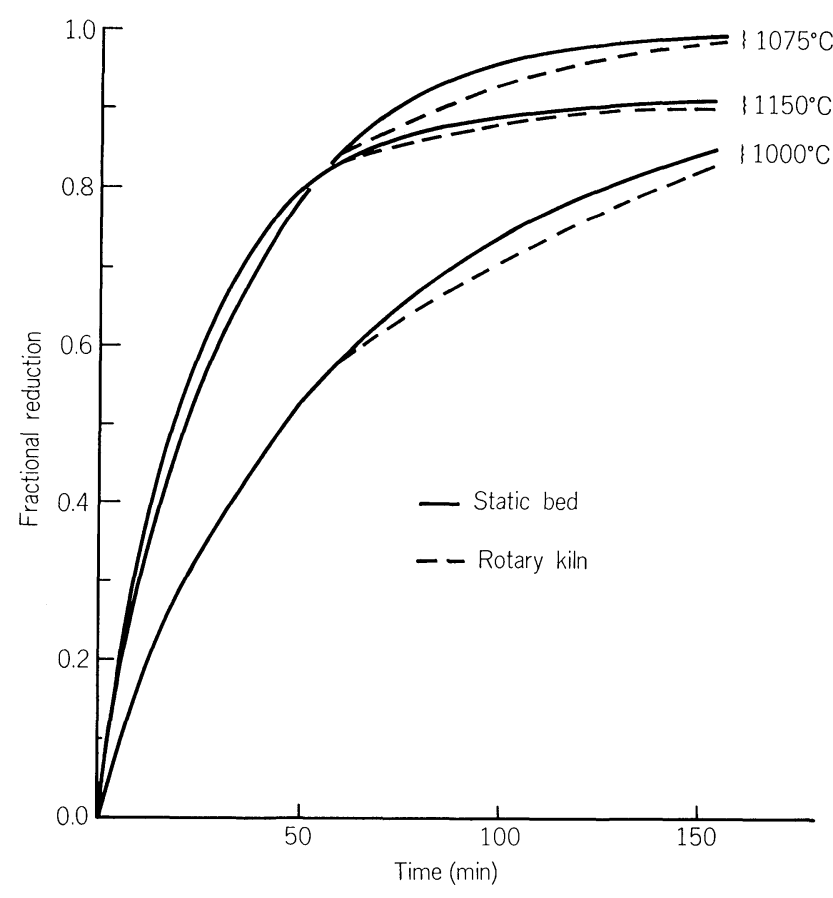

Fig. 2. Comparison of reaction rates in the static bed with rotary kiln results.
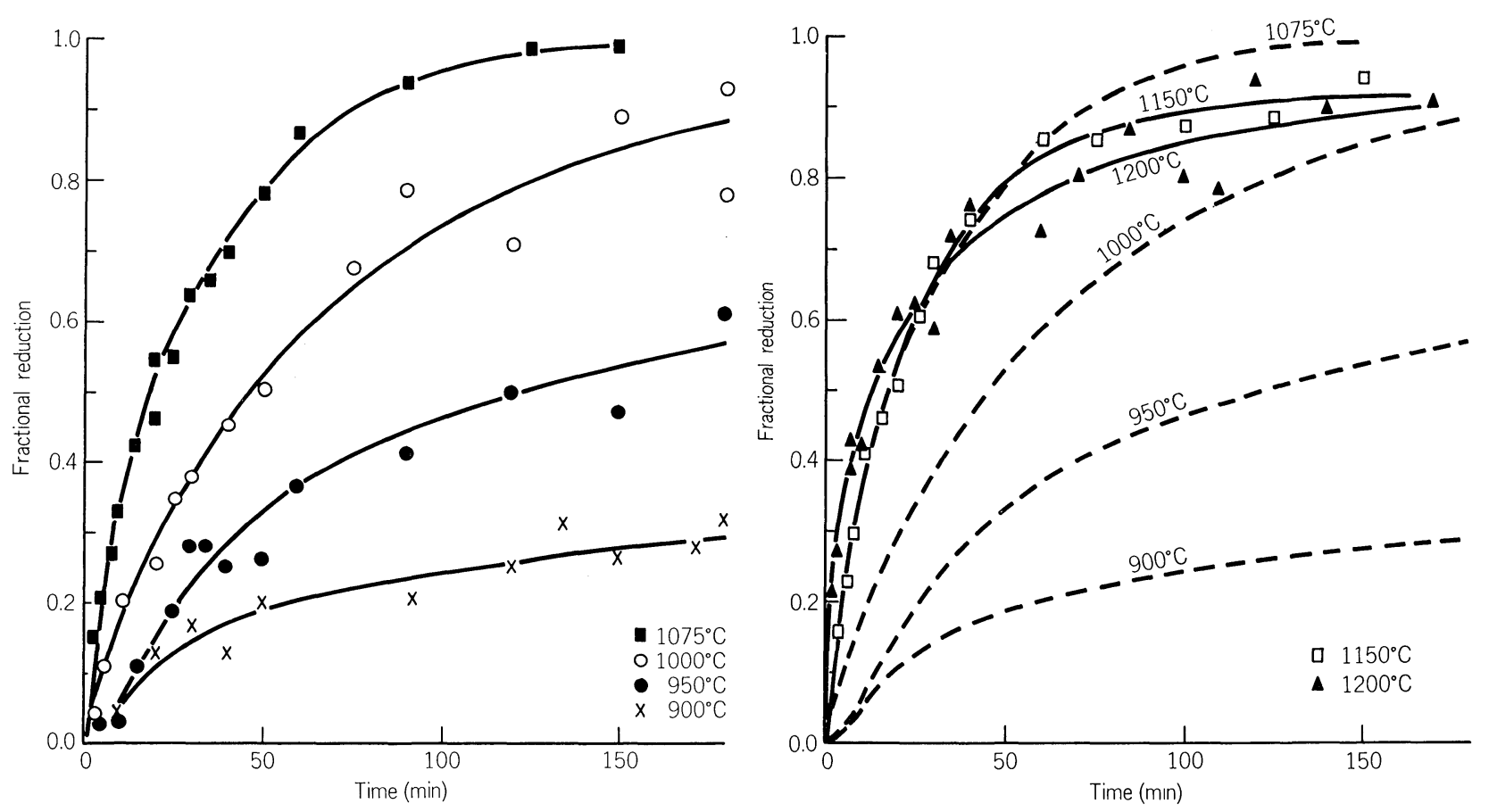

Fig. 1. Extent of reduction vs. reaction time for pellets reduced at (a) $900^{\circ} \sim 1075^{\circ} \mathrm{C}$ and (b) $1150^{\circ} \sim 1200^{\circ} \mathrm{C}$.

* The first few tests were carried out using lidded crucibles to minimize oxidation of the char during the heating and reduction periods. However, even in the open crucibles used in later tests, oxidation of the char was limited to the surface layers only. 


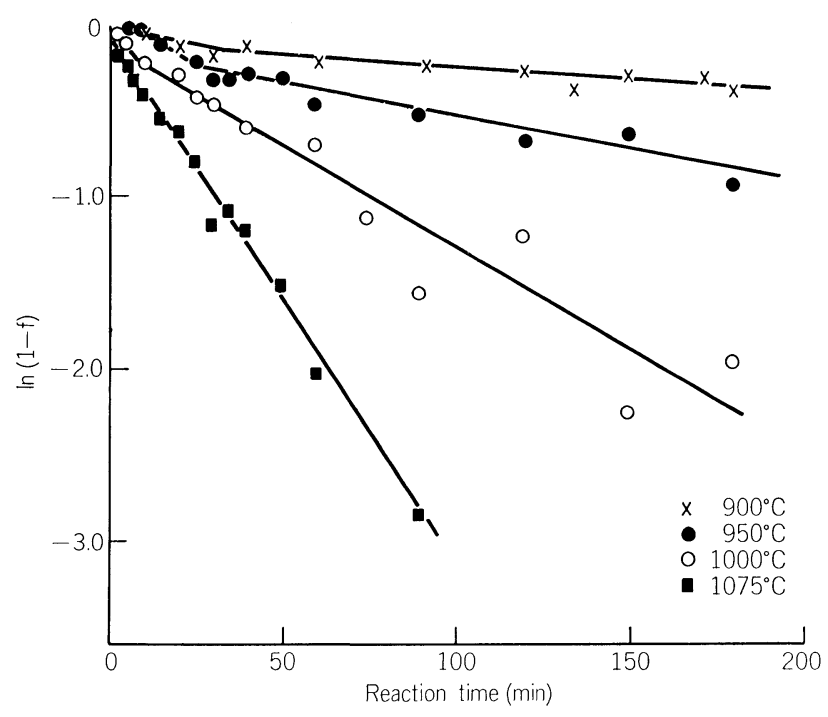

Fig. 3. Results of reduction tests at $900^{\circ} \sim 1075^{\circ} \mathrm{C}$ plotted according to first order reaction kinetics.

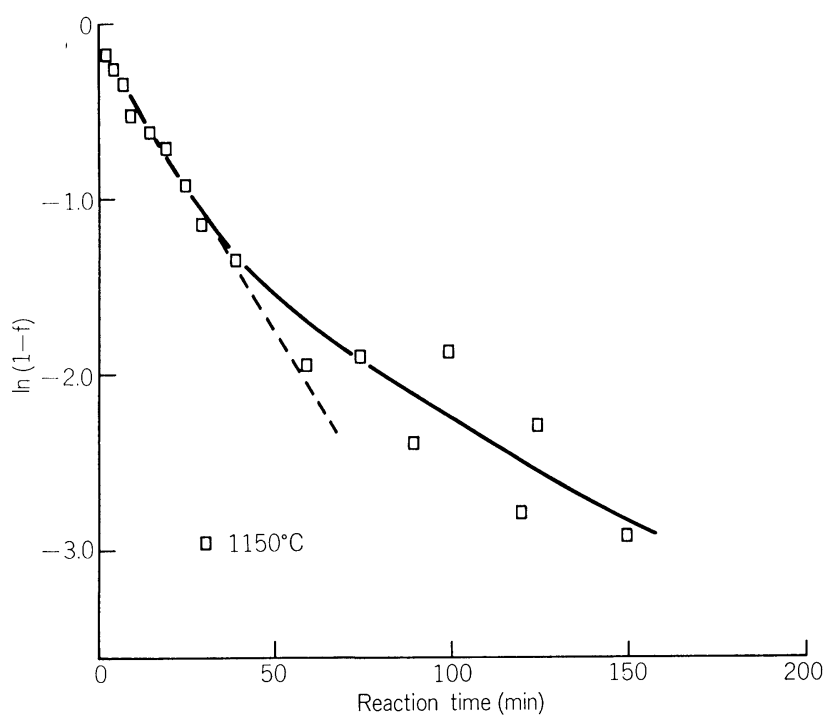

Fig. 4. Results of reduction tests at $1150^{\circ} \mathrm{G}$ plotted assuming first order reaction kinetics.

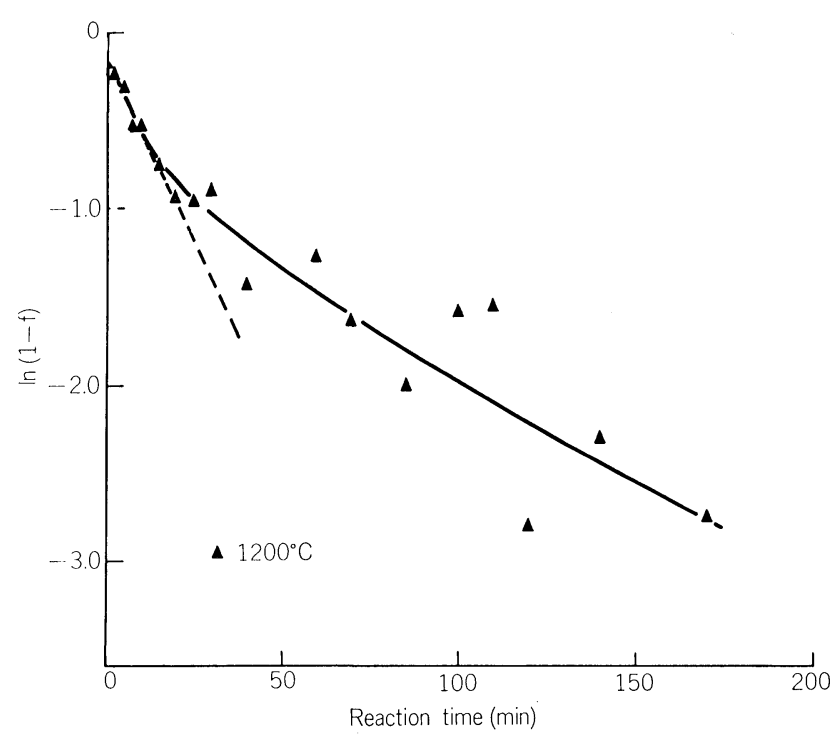

Fig. 5. Results of reduction tests at $1200^{\circ} \mathrm{C}$ assuming first order reaction kinetics. iron was formed almost from the beginning of the reaction and only one stage was observed.

At temperatures in excess of $1075^{\circ} \mathrm{C}$, the results deviated from the initial linear sections of the plots, the deviation occurring at lower extents of reduction as the temperature increased (see Figs. 4 and 5).

In general, these lines do not pass through the origin, and this can be attributed to additional reaction steps at short times, which have not been investigated at this stage. For instance the time taken to build up the carbon monoxide concentration could cause an induction period (see $950^{\circ} \mathrm{C}$ curve) or conversely carbon gasification could initially be very rapid as suggested by $\mathrm{Rao},{ }^{12)}$ thus causing a positive intercept on the ordinate.

\section{Discussion}

The reduction of iron oxides by carbon in all but high vacuum systems occurs through the intermediates $\mathrm{CO}$ and $\mathrm{CO}_{2}$. The first step in the sequence is the formation of $\mathrm{CO}$ by the reaction of carbon with the free atmospheric oxygen which is entrapped in the system during the pellet and carbon transfer operations,

$$
\mathrm{C}_{(\mathrm{s})}+1 / 2 \mathrm{O}_{2(\mathrm{~g})} \longrightarrow \mathrm{CO}_{(\mathrm{g})}
$$

Carbon monoxide can also be generated at point contacts between the iron oxides $\left(\mathrm{Fe}_{2} \mathrm{O}_{3}, \mathrm{Fe}_{3} \mathrm{O}_{4}, \mathrm{FeO}\right)$ and carbon, i.e.,

$$
\mathrm{Fe}_{a} \mathrm{O}_{b}+n \mathrm{C} \longrightarrow m \mathrm{Fe}_{c} \mathrm{O}_{d}+n \mathrm{CO}
$$

where, $a=2,3$, or 1 ; when $b=3,4$ or $1 ; c=3,1$ or 1 ; $d=4,1$ or 0 $n=1 / 3,1$ or 1 $m=2 / 3,3$ or 1 .

The $\mathrm{CO}$ formed from these reactions then reacts with the iron oxides to form $\mathrm{CO}_{2}$,

$$
\mathrm{Fe}_{a} \mathrm{O}_{b}+n \mathrm{CO} \longrightarrow m \mathrm{Fe}_{c} \mathrm{O}_{d}+n \mathrm{CO}_{2}
$$

where the subscripts have the same values as in Eq. (2). The $\mathrm{CO}_{2}$ then reacts with excess carbon to regenerate $\mathrm{CO}$.

$$
\mathrm{C}_{(\mathrm{s})}+\mathrm{CO}_{2(\mathrm{~g})} \longrightarrow 2 \mathrm{CO}_{(\mathrm{g})}
$$

and the cycle is repeated.

Fruehan $^{19)}$ has observed that the rate of carbon gasification by $\mathrm{CO}_{2}$ is less than the rate of reduction of iron oxide by $\mathrm{CO}$ below about $1100^{\circ} \mathrm{C} .{ }^{21,22)}$ Therefore the carbon gasification or Boudouard reaction (reaction 4) would be expected to control the overall reaction rate.

The gasification of carbon has been found to obey first-order kinetics and can be approximated by ${ }^{19,22)}$

$$
\ln (1-f)=-k t \text {. }
$$

where $f$ is the fraction of the reaction completed, $k$ is a rate constant for a specific gas composition and temperature, and $t$ is the reaction time.

Bearing in mind that the carbon gasification reaction is assumed to be rate controlling, the values of the rate constant, $k$, were calculated from the slopes of 
the linear portions of the rate curves (Figs. 3 to 5) and are shown in Fig. 6 as an Arrhenius diagram. This figure also shows the results of other workers ${ }^{12,19)}$ for the reaction of intimate mixtures of finely divided iron oxides with various types of carbon reductants.

The apparent activation energies calculated from the linear portions of the curves covered the narrow range of $290 \sim 335 \mathrm{~kJ} / \mathrm{mol}$ (approximately $70 \sim 80$ $\mathrm{kcal} / \mathrm{mol}$ ). This range of values agrees closely with the apparent activation energies derived by other authors for the oxidation of carbon by $\mathrm{CO}_{2}{ }^{21}$ ) and the reduction of iron oxides under carbon gasification control. ${ }^{10,16)}$

The values of the published rate constants, $k$, at any given temperature depend strongly on the type of carbon used as the reductant (see Fig. 6). The highest rate constants were obtained using high-activity coconut charcoal and the lowest using relatively low-activity coke. The present results, obtained at temperatures below $1000^{\circ} \mathrm{C}$ using carbonized coal, were intermediate between the two extremes.

Above $1000^{\circ} \mathrm{C}$, the present results deviated from the straight line plot for apparent activation energy. This effect was also noted by Fruehan, ${ }^{19)}$ as shown in Fig. 6 in the case of coconut charcoal and coal char. Fruehan postulated that the deviation might be due to a change in the reaction control from purely carbon

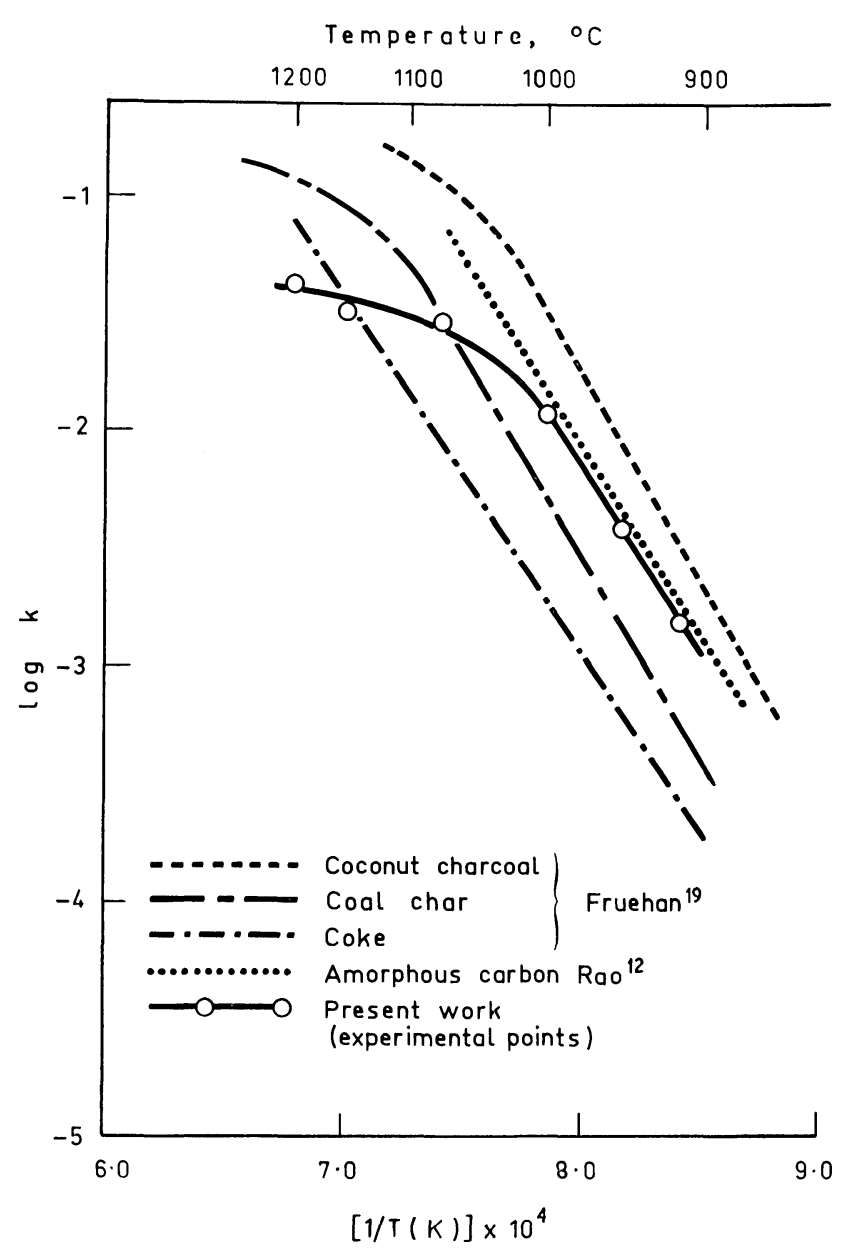

Fig. 6. Rate constants for the reduction of iron oxides with various carbon types. gasification to mixed control in which the rate of reduction of $\mathrm{FeO}$ by $\mathrm{CO}$ approaches the rate of carbon gasification at high temperatures. It would therefore be expected that, at high temperatures, the greater the reactivity of the carbon used the more likely it would be that the reaction would be controlled by the reduction of $\mathrm{FeO}$ to Fe. Fruehan's conclusion is supported by the results shown in Fig. 6 in which the rate constants began to level off at lower temperatures for coconut charcoal than for coal char. No deviation was observed for the low activity coke at temperatures up to $1200^{\circ} \mathrm{C}$. Similarly, the higher activity amorphous carbon used in Rao's ${ }^{12)}$ work did not show a rate depression; however, the highest temperature examined was only $1087^{\circ} \mathrm{C}$.

The deviation observed in the present work with carbonized coal commenced at a lower temperature and was more severe than that observed by Fruehan. Although a change in the rate controlling mechanism from carbon gasification to mixed control probably contributed to the depression, the most likely factor was the difference in the reaction configuration used in the present work. Whereas in most of the previous work, the reductants and reactants were finely divided and intimately mixed, in the present work the reductant was placed externally to $12-\mathrm{mm}$ dia. porous pellets. Thus in the previous work, the reacting gases were generated in close proximity to the reacting iron oxides and gas diffusion should not have had a great influence on the reduction rates. However, in the present work, the diffusion paths for the gaseous reductant $(\mathrm{CO})$ and product $\left(\mathrm{CO}_{2}\right)$ were relatively long. With increasing temperature, the rate of reduction of $\mathrm{FeO}$ by $\mathrm{CO}$ increases and if $\mathrm{CO}$ cannot be supplied to the reacting interfaces within the pellets at a sufficient rate, gas diffusion becomes rate controlling and the increase in the overall reaction rate with temperature decreases.

Apart from the temperature effect on the rate constants measured from the slopes of the linear portions of the $\ln (1-f) v s . t$ curves in Figs. 3 to 5, there was also a strong deviation from linearity at higher degrees of reduction for the pellets reduced at temperatures in excess of $1075^{\circ} \mathrm{C}$ (Figs. 4 and 5). In order to establish the reasons for the deviation, a microscopic study of the pellets reduced in the static bed was undertaken.

In the pellets partially reduced at $900^{\circ} \sim 1075^{\circ} \mathrm{C}$, metallic iron was found to be distributed continuously throughout the pellet cross-section. A typical area with white metallic iron forming on light grey wustite grains is shown in Photo. 1. The absence of a welldefined unreacted core in the pellets reduced at low temperatures indicated that gas diffusion was not rate controlling.

Photograph 2 shows the microstructure of the central area of a pellet reduced at $1075^{\circ} \mathrm{C}$ for $60 \mathrm{~min}$ (approx. 85\% reduced). The light grey areas are wustite grains, while the darker grey phase is a glassy slag, formed by the reaction of the wustite with the small amounts of primary slag present in the original unreduced pellets. The primary slag was originally 


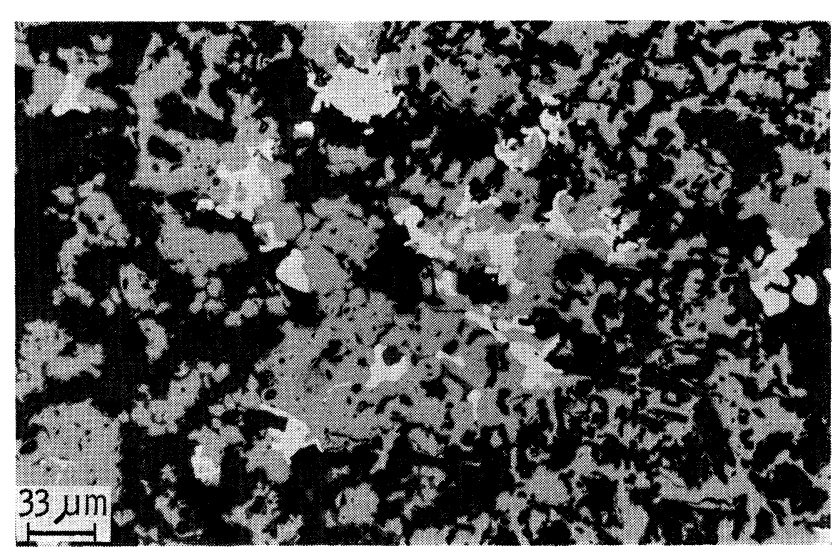

Photo. 1. Metallic iron (white) growing on wustite grains (light grey) in a pellet reduced at $1075^{\circ} \mathrm{C}$ for $40 \mathrm{~min}$.

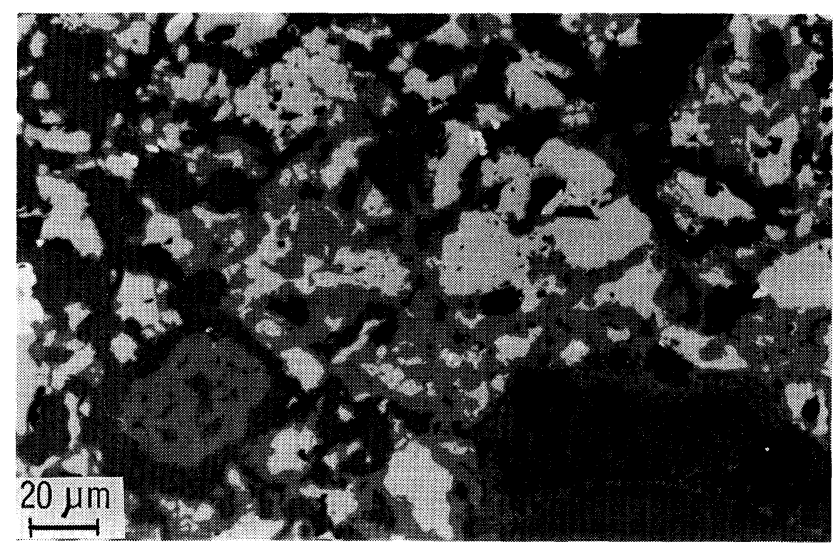

Photo. 2. Slag formation (dark grey) in the centre of a pellet reduced at $1075^{\circ} \mathrm{C}$ for $60 \mathrm{~min}$.

formed during the previous induration (or firing) process by chemical combination of the gangue minerals (mainly $\mathrm{SiO}_{2}$ and $\mathrm{Al}_{2} \mathrm{O}_{3}$ ) in the ore with the flux $(\mathrm{CaO})$ incorporated in the balling stage. The glassy slag formed only towards the centres of the pellets reduced for relatively long times. Apparently a considerable time $\left(e . g ., 60 \mathrm{~min}\right.$ at $1075^{\circ} \mathrm{C}$ ) was required for the combination of wustite $(\mathrm{FeO})$ and the other slag-forming components in the pellets. In regions close to the pellet surfaces, where a higher reduction potential prevailed, wustite was reduced to metallic iron before appreciable slagging occurred. No slags were detected in pellets reduced at temperatures less than $1075^{\circ} \mathrm{C}$.

At higher temperatures, slags formed in the pellet cores at shorter times. Photograph 3 shows the central region of a pellet reduced at $1150^{\circ} \mathrm{C}$ for $40 \mathrm{~min}$. The rounded, light grey grains consist of wustite which has partially dissolved in the glassy slag. With increasing times (and temperatures) the slag areas become more extensive and change from a homogeneous glass to a two-phase lath-like structure. A typical example is shown in Photo. 4 (pellet reduced at $1150^{\circ} \mathrm{C}$ for $150 \mathrm{~min}$ ). With continued dissolution of wustite, the slag changed from a lath-like to a predominantly dendritic form on cooling. The range of slag structures encountered in this study is illustrated by

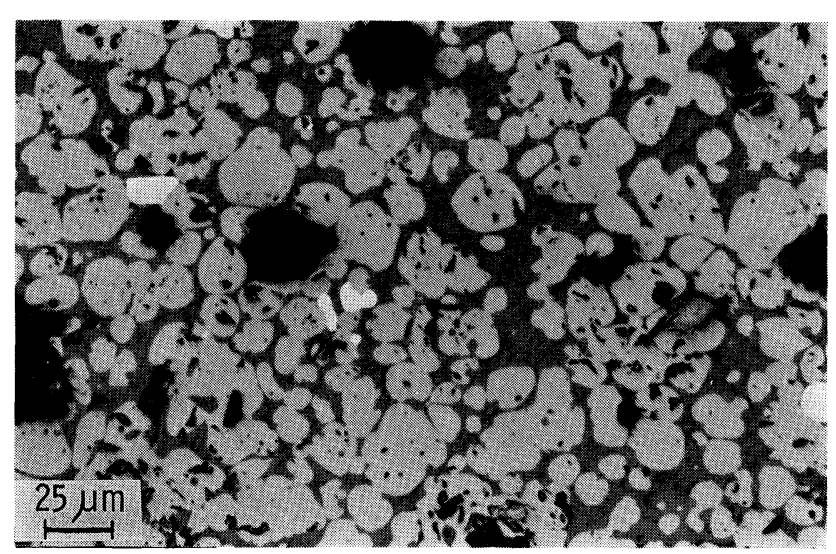

Photo. 3. Rounded grains of wustite dissolving in slag. Pellet reduced at $150^{\circ} \mathrm{C}$ for $40 \mathrm{~min}$.

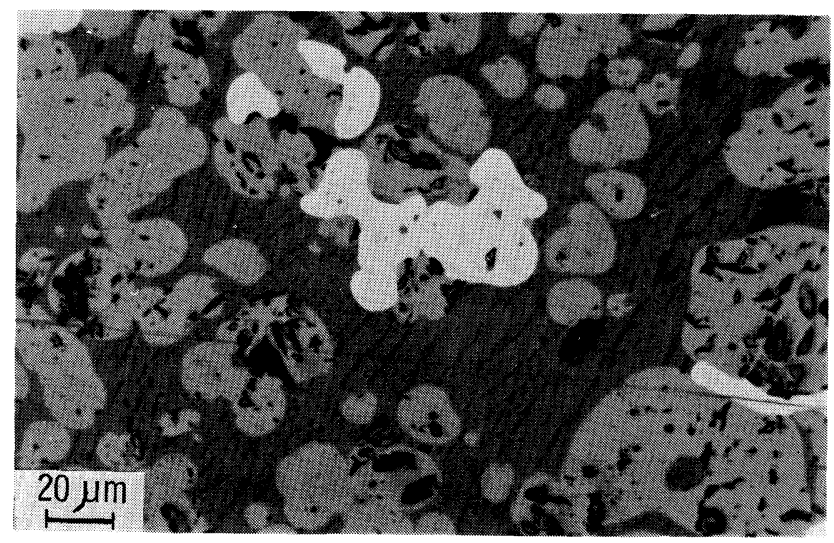

Photo. 4. Wustite grains dissolving into a lath-like slag phase. Pellet reduced at $1150^{\circ} \mathrm{C}$ for $150 \mathrm{~min}$.

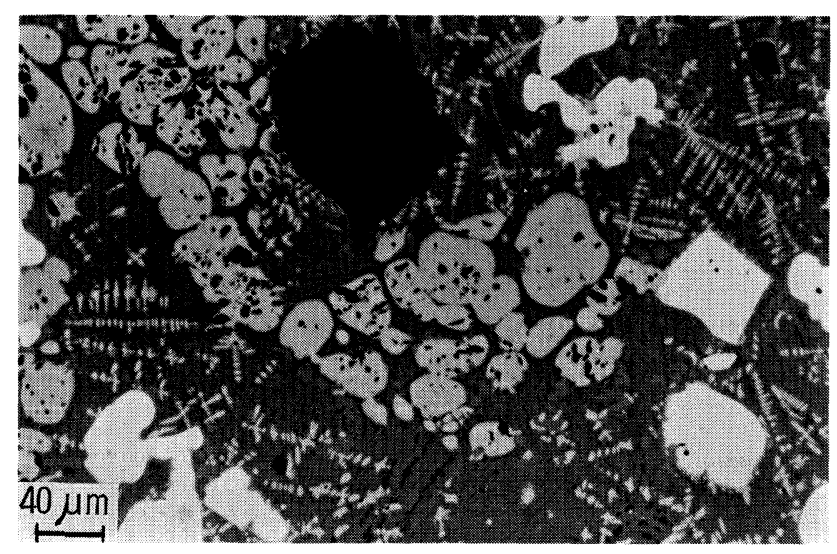

Photo. 5. Photomicrograph of the central region of a pellet reduced at $1200^{\circ} \mathrm{C}$ for $140 \mathrm{~min}$ illustrating a range of slag structures.

\section{Photo. 5.}

Examination of numerous photomicrographs showed that the onset of extensive slagging in the interiors of the pellets reduced at $1150^{\circ}$ and $1200^{\circ} \mathrm{C}$ corresponded closely to the point of deviation of the reduction rate results from the linear portions of the curves shown in Figs. 4 and 5. The slag formation was accompanied by consolidation of the pellet cores which led to the development of concentric shrinkage cracks. This is illustrated in Photo. 6 which shows the full 
cross-section of a pellet reduced at $1150^{\circ} \mathrm{C}$ for 150 min. Gracking did not occur in pellets reduced at temperatures below $1150^{\circ} \mathrm{C}$. The consolidation of the pellet structures further impeded the access of reducing gas to the pellet interiors and gas diffusion became even more restricted at high temperatures.

At relatively long reaction times and high temperatures, the slags became almost completely enclosed by shells of non-porous metallic iron (Photo. 7). At this stage, reduction could only continue by solid state diffusion of the reaction species through the iron barriers and the reduction rates further declined.

The results of the static bed tests were very similar to those previously reported for the reduction of the same pellets with a solid reductant in a laboratory rotary kiln ${ }^{20}$ ) (Fig. 2). The only major difference in the processing conditions was that in the former work the rotary tumbling action of the kiln tended to cause some surface densification and pore closure of the reduced pellets, ${ }^{23)}$ but this apparently had only a minor retarding effect on the reduction rates, the major rate limiting process being the internal slag formation and consolidation of the pellet cores.

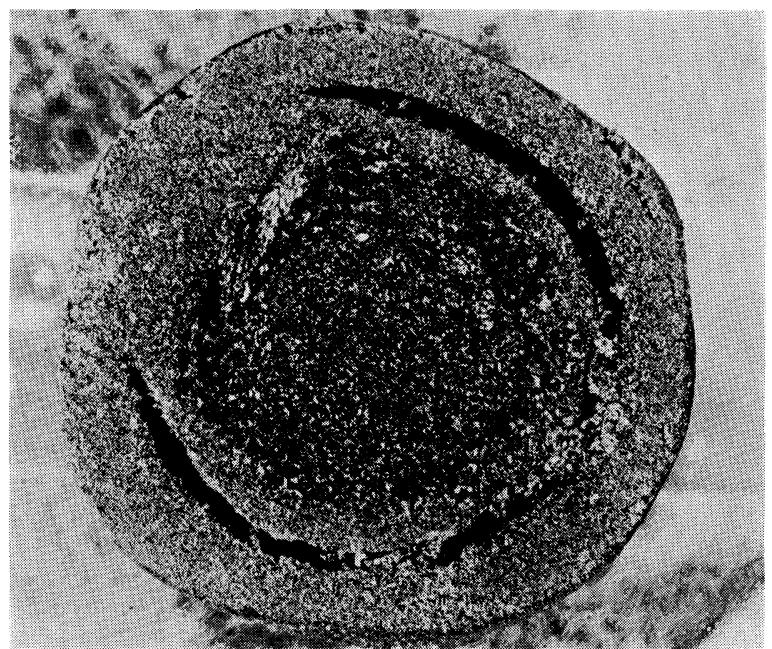

Photo. 6. Cross section of a pellet reduced at $1150^{\circ} \mathrm{C}$ for 150 min showing concentric cracking around the partially reduced core.

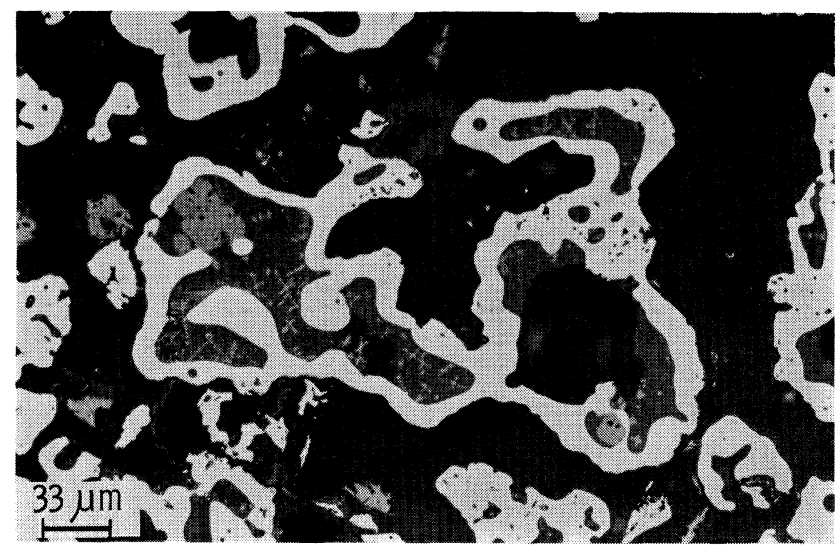

Photo. 7. Microstructure of a pellet reduced at $1150^{\circ} \mathrm{G}$ for 150 min showing slag enclosed by an envelope of metallic iron.
Overall the work has shown that the reduction kinetics in the range $900^{\circ} \sim 1000^{\circ} \mathrm{C}$ for the fired pellets reduced by an external solid reductant appear to be similar to those for finely divided pure iron oxides reduced with an intimate mixture of carbon, i.e. the reaction rates are controlled primarily by the rate of gasification of the solid reductant. However, at temperatures in excess of $1000^{\circ} \mathrm{C}$, the rate of diffusion of $\mathrm{CO}$ and $\mathrm{CO}_{2}$ from the external reductant into and out of the pellet interiors becomes significant, with the result that the reaction rates are depressed compared with those of the finely divided systems in which the reductant and the reactant are in close proximity. At temperatures in excess of $1075^{\circ} \mathrm{C}$, slag formation in the pellet interiors results in a further lowering of the reduction rates-an effect which does not occur in pure iron oxide/carbon reaction systems.

These observations suggest that it may be possible to extend the upper temperature limit of kilns treating commercial pellets by decreasing the quantities of slag-forming constituents in the pellets by using higher-grade ores and minimum amounts of bonding agents. It may also be possible to increase the melting point of the slags by control of the slag composition. For example, some recent work ${ }^{24)}$ has shown that the use of dolomite or magnesium oxide as a pellet bonding agent significantly increases the softening and melting points of pellets under reducing conditions.

Work is continuing on a more detailed study of the various rate controlling steps. The use of highly reactive coals and chars will be investigated in an attempt to operate the process efficiently at lower temperatures to avoid the high temperature rate limitations. In addition, a study will be made of the effect of gangue content and bonding agent type on the pellet reduction rates at high temperatures.

\section{Conclusions}

(1) The reduction rates of pellets reduced by carbonized coal in a static bed were found to be similar to the reduction rate of the pellets reduced in a small batch rotary kiln.

(2) From $900^{\circ} \sim 1000^{\circ} \mathrm{C}$, the reduction rates of pellets reduced in a static bed are controlled by the rate of gasification of the carbonized coal reductant used.

(3) At temperatures in excess of $1000^{\circ} \mathrm{C}$, the diffusion of $\mathrm{CO}$ and $\mathrm{CO}_{2}$ into and out of the pellets begins to influence the reduction rates. At this stage both carbon gasification and gas diffusion in series control the overall reduction rate.

(4) At temperatures in excess of $1075^{\circ} \mathrm{C}$, extensive internal slagging occurs, accompanied by pellet consolidation. This further impedes the access of reducing gas into the unreduced pellet cores and further lowers the reduction rate.

(5) At an advanced stage of the reduction process, and at temperatures in excess of $1150^{\circ} \mathrm{C}$, the slag regions in the interior of the pellets become enclosed by non-porous shells of metallic iron. Reduction can only continue by solid-state diffusion of the 
reacting species through the shells. This results in a further depression of the reaction rate.

(6) The results obtained should be of assistance in optimizing the performance of commercial plants of either the rotary kiln or shaft kiln types.

\section{REFERENCES}

1) H. Serbent and W. Janke: "SL/RN Process: Production of Sponge Iron Using Solid Reductants", Paper presented at the seminar " Direct Reduction of Iron Ore: Technical and Economic Aspects", Economic Commission for Europe Steel Comm., Bucharest, Sept., (1972).

2) G. Meyer, R. Wetzel and U. Bongers: "The Krupp Sponge Iron Process-Its Products and Applications", Paper presented at the seminar, "Direct Reduction of Iron Ore: Technical and Economic Aspects", Economic Commission for Europe Steel Comm., Bucharest, Sept., (1972).

3) S. Sakurai: "Recycling of Oxide Fines in a Steel Plant," Paper presented to "Pollution in Steel Industry", IISI, Tokyo, March, (1974).

4) A. Barbi: Iron Steel Intern., 50 (1977), 229.

5) F. Colautti and A. Barbi: Chem. Eng., 89 (1977), No. 9, 78

6) B. G. Baldwin: JISI, 179 (1955), 30.

7) T. S. Yun: Trans. ASM, 54 (1961), 129.

8) E. Bicknese and R. Clark: Trans. AIME, 236 (1966), 2.

9) G. D. McAdam, R.E.A. Dall and T. Marshall: N.Z.J.
Sci., 12 (1969), 669.

10) K. Otsuka and D. Kuni: J. Chem. Eng. Japan., 2 (1969), 46.

11) P. Ghosh and S. N. Tiwari: JISI, 208 (1970), 255.

12) Y. K. Rao: Met. Trans. AIME, 2 (1971), 1439.

13) Y. K. Rao: Chem. Eng. Sci., 29 (1974), 1933 and 1435.

14) H. Y. Sohn and J. Szekely: Chem. Eng. Sci., 28 (1973), 1789.

15) N. S. Srinivasan and A. K. Lahiri: Met. Trans. 8B (1977), 175.

16) N. S. Srinivasan and A. K. Lahiri: Met. Trans., 6B (1975), 269.

17) M. Kawakami, L. L'Estrade and K. S. Goto: Scand. J. Met., 6 (1977), 62.

18) G. D. McAdam, D. J. O'Brien and T. Marshall: Ironmaking and Steelmaking, 4 (1977), 1.

19) R. J. Fruehan: Met. Trans., 8B (1977), 279.

20) A. L. Morrison, J. K. Wright and K. McG. Bowling: Ironmaking and Steelmaking, 5 (1978), 32.

21) E. T. Turkdogan and J. V. Vinters: Carbon, 7 (1969), 101.

22) E. T. Turkdogan and J. V. Vinters: Carbon, 8 (1970), 39.

23) A. L. Morrison, J. K. Wright and K. McG. Bowling: Ironmaking and Steelmaking, 5 (1978), 39.

24) O. Saeki, K. Taguchi and I. Nishida: "Blast Furnace Performance Using Dolomite Fluxed Pellets at Kakogawa Works ”, Agglomeration 77, AIME, Atlanta, March, (1977). 